DEMOGRAPHIC RESEARCH

VOLUME 28, ARTICLE 11, PAGES 313-340

PUBLISHED 15 FEBRUARY 2013

http://www.demographic-research.org/Volumes/Vol28/11/

DOI: $10.4054 /$ DemRes.2013.28.11

Research Article

\title{
Does the kin orientation of a British woman's social network influence her entry into motherhood?
}

\section{Paul Mathews \\ Rebecca Sear}

(C) 2013 Paul Mathews \& Rebecca Sear.

This open-access work is published under the terms of the Creative Commons Attribution NonCommercial License 2.0 Germany, which permits use, reproduction \& distribution in any medium for non-commercial purposes, provided the original author(s) and source are given credit.

See http:// creativecommons.org/licenses/by-nc/2.0/de/ 


\section{Table of Contents}

$\begin{array}{lll}1 & \text { Introduction } & 314\end{array}$

$2 \quad$ Literature review 315

$2.1 \quad$ Social networks and fertility 315

2.2 What effect does the kin composition of a social network have on 316 fertility, and why?

2.3 Proximate mechanisms through which kin may influence fertility 317

$\begin{array}{lll}2.4 & \text { Potential confounding factors } & 319\end{array}$

$3 \quad$ Data and methods 320

3.1 Kin orientation and social networks 321

3.2 Control variables $\quad 324$

3.3 Other considerations 326

4 Results $\quad 326$

5 Discussion 331

6 Acknowledgments 333

References 334 


\title{
Does the kin orientation of a British woman's social network influence her entry into motherhood?
}

\author{
Paul Mathews ${ }^{1}$ \\ Rebecca Sear ${ }^{2}$
}

\begin{abstract}

\section{BACKGROUND}

The influence of family and friends on an individual's fertility has long been an important topic within demography. Researchers who focus on social network effects and evolutionary demography have shown a renewed interest in this issue in recent years. However, only a few studies have been conducted in contemporary low-fertility, resource-rich settings.
\end{abstract}

\section{OBJECTIVE}

This study investigates whether a British woman's entry into motherhood (i.e., her first birth) is influenced by the kin orientation of her close social network. Specifically, we test the prediction derived from evolutionary theory that individuals with a kin-oriented network will have higher fertility than those with fewer relatives in their close social networks. We consider two potential proximate mechanisms by which kin may influence fertility. First, relatives could provide practical resources, such as childcare, which reduce the costs of reproduction, thereby increasing fertility. Second, family members might communicate relatively pro-natal messages that could help to "persuade" childless women to become mothers.

\section{METHODS}

We use data from the British Household Panel Study (1992 to 2003), and base the degree of kin orientation on the number of relatives a woman includes when identifying her three closest non-household associates. We conduct a discrete-time event history analysis to measure the risk of first birth, controlling for household composition and socio-economic background.

\footnotetext{
${ }^{1}$ University of Essex, United Kingdom. E-mail: pmathews@essex.ac.uk.

${ }^{2}$ London School of Hygiene and Tropical Medicine, United Kingdom.
} 


\section{RESULTS}

We find that when a woman has more kin in her close social network, her risk of having a first birth increases at all ages. This suggests that relatives may influence fertility behaviour in this contemporary resource-rich population. Both of our proposed proximate mechanisms may be important in driving this effect.

\section{Introduction}

Interest in the relationship between relatives and reproduction has waxed and waned. From the end of World War II until the 1970s, researchers devoted substantial attention to this area of study, focusing particularly on the question of whether couples living within extended families had higher fertility than those living in nuclear households (Davis and Blake 1956; Young and Wilmott 1957). The interest in this topic then seemed to decline, partly due to methodological and conceptual problems (Burch and Gendell 1970). However, two recent developments in demographic research have led to a renewed focus on this relationship. First, seminal work in the 1980s on models of cultural diffusion established the importance of social networks for fertility behaviour (Boyd and Richerson 1985; Cleland and Wilson 1987). Second, increasing interactions between evolutionary biology and demography have led to greater interest in the effects of kin on reproduction. Evolutionary biology's theory of inclusive fitness posits that genetic relatives have more reproductive interests in common than non-relatives (Hamilton 1964). Evolutionary demographers are therefore specifically interested in kin, since they are the social network members who should, theoretically, have the most influence on reproductive behaviour.

The number of empirical studies that have tested inclusive fitness predictions on human demographic patterns is small, but is growing rapidly. This research has largely been conducted on high-fertility populations. In this study, we use a dataset from a lowfertility population, the UK, to test whether the risk of first birth at all ages is influenced by kin orientation. As a secondary aim, we examine the potential pathways through which kin could influence reproductive behaviour, by investigating whether the frequency of contact with kin, or the geographical proximity of these relatives, matters more. 


\section{Literature review}

\subsection{Social networks and fertility}

In recent years, a substantial amount of research has been done on the effects of social network characteristics on various reproductive attitudes and behaviours (Montgomery and Casterline 1993; Kohler 1997; Montgomery and Chung 1999; Kohler, Behrman, and Watkins 2000; Kohler, Behrman, and Watkins 2001; Behrman, Kohler, and Watkins 2002; Bernardi 2003; Madhavan, Adams, and Simon 2003; Rindfuss et al. 2004; Helleringer and Kohler 2005; Sandberg 2005; Kuziemko 2006; Musalia 2006; Avogo and Agadjanian 2008; Borgerhoff Mulder 2009; Keim, Klarner, and Bernardi 2009; Mace and Colleran 2009; Hensvik and Nilsson 2010). Relatively few of these studies on social networks have focused on actualised fertility outcomes, with the exception of Madhavan et al (2003), Kuziemko (2006), and Hensvik and Nilsson (2010). Instead, researchers have mainly concentrated on the diffusion of contraceptive knowledge and social norms concerning reproduction. These studies have tended to compare the relative effects of information spreading (social learning) and the social acceptability of behaviours (social influence) (see Montgomery and Casterline 1996). This type of research requires the measurement and analysis of a social network's density: i.e., an examination of how closely other individuals (alters) are tied to one another. High-density networks will facilitate social influence, while low-density networks are conducive to the spread of information. Less attention has been paid to the composition of the network, with only a few studies looking at the question of whether alters are genetically related to the measured individual (although there are exceptions: e.g., Madhavan, Adams, and Simon 2003; Bernardi 2003; Musalia 2005; Kuziemko 2006; Keim, Klarner, and Bernardi 2009; Mace and Colleran 2009; Borgerhoff Mulder 2009).

These studies have also tended to concentrate on high-fertility populations among whom substantial changes in fertility regulation are taking place, and have therefore mainly focused on the question of whether a decline in fertility spreads through social networks. Meanwhile, the question of whether fertility behaviour in other contexts is also influenced by social networks and kin interactions has rarely been tested. We have found only two quantitative studies of low-fertility populations that investigated whether fertility behaviours are affected by social networks, and those studies looked at quite different types of network (co-workers in Sweden (Hensvik and Nilsson 2010) and siblings in the US (Kuziemko 2006)). Qualitative studies of low-fertility populations have indicated that kin interactions may influence fertility preferences (see Bernardi (2003) for Italy and Keim, Klarner, and Bernardi (2009) for Germany). 


\subsection{What effect does the kin composition of a social network have on fertility, and why?}

Natural selection favours genes that act to increase their frequency in subsequent generations. By definition, relatives share one another's genes. Evolutionary theory therefore predicts that relatives will be interested in increasing one another's reproductive success, provided the costs of increasing that relative's reproductive success do not outweigh the benefits obtained (weighted by the coefficient of relatedness, or the probability that any gene will be shared between the two relatives (Hamilton 1964)). This "inclusive fitness" includes the successful reproduction of both the individual and of his or her relatives in the measurement of total Darwinian fitness. Hamilton's inclusive fitness theory is vital for explaining the reproductive behaviour of many species, such as social insects, and has recently been used as a framework for interpreting variation in human fertility at both the micro and the macro levels. It has been argued, for example, that the demographic transition from high to low fertility may have been partly caused by a decline in kin influence (Turke 1989; Newson, et al. 2005). These authors speculated that during the process of "modernisation" kin networks fragment (see Ruggles (1994) for a debate on the extent of this process). A weakening of kin networks reduces the opportunities for kin to encourage the reproduction of their relatives, and may also increase the costs of reproduction for parents, as kin are less able to help raise children.

Such an approach has also been applied successfully to individual-level analysis of fertility variance. Evolutionary anthropologists have demonstrated in a number of highfertility populations an association between the presence of certain kin and fertility (see reviews by Mace and Sear (2005) and Sear and Coall (2011)). Such studies have tended to use small-scale anthropological datasets, and have often measured kin influence simply as the presence (or absence) of a particular relative (mother, father, grandmother, etc.) in the community. Nevertheless, this literature suggests that incorporating measures of kin influence may be a fruitful line of enquiry when investigating fertility behaviour.

It should be noted, however, that it is not always in a relative's interests to be blindly pro-natal. Simply increasing the total number of children born to an individual is unlikely to increase genetic representation in future generations. Starting too early or having too many closely spaced children may result in maternal depletion and suboptimal investment in each child. It is therefore expected that relatives will act to delay childbearing in environments in which a delay allows the individual to acquire resources that substantially enhance the fitness outcomes of children born later. We conducted a systematic review of kin influence on fertility, and found precisely this effect in the four relevant UK studies. As in most other developed societies, a parental presence in the household decreased the likelihood of teenage pregnancy or early first 
births (Sear and Mathews 2009; the UK studies were Kiernan 1992; Russell 1994; Kiernan and Hobcraft 1997; Manlove 1997). Context matters: relatives should only encourage childbearing if the conditions are right for any child produced to become a "successful" adult (success is measured here in terms of fitness rather than socioeconomic status; i.e., whether the child is successful at surviving, mating, reproducing, and supporting children of her own). Despite this caveat, we predict that kin should on aggregate encourage reproduction. Thus, the presence of kin should increase the risk that an individual will have at least one child during adulthood.

\subsection{Proximate mechanisms through which kin may influence fertility}

Inclusive fitness theory explains why relatives in general have an interest in improving each other's reproductive success, but it does not explain how this is done. Research on these proximate mechanisms is less well developed, but two possible pathways of influence have been suggested.

First, relatives can assist reproduction through the provision of resources and practical assistance (Turke 1989). In resource-scarce environments, providing economic resources or assistance could improve the health and fecundity of a relative, and thus may directly affect fertility. While such direct effects on fecundity are unlikely to be seen in resource-rich environments, the provision of economic resources in this context might encourage childbearing by lowering the costs, or the perceived costs, of having children. The main reproductive resource relatives provide is, according to Turke, childrearing assistance. Childcare considerations are very relevant in contemporary Western societies. Childcare can be extremely costly if purchased directly, or indirectly through reduced (normally female) employment and career opportunities. If "free" childcare is available from a relative, this will lower the barriers to childbearing. Empirical research for the UK has shown that relatives regularly provide childcare, with some studies showing that help with childcare has increased in recent years due to greater female employment (Gray 2005). Many working mothers also believe childcare provided by their relatives is "better" than care provided by nurseries and child minders (Wheelock and Jones 2002). Hank and Kreyenfeld (2003) found for Germany that having parents in the same town increased the likelihood that individuals would have a first child; a result they attributed to the potential availability of childcare. Parental availability was shown to have had a similar effect in Italy (Del Boca 2002). In a study conducted in Norway, however, researchers found that an adult woman was less likely to have had a first child if her mother lived in the same municipality, although no partnership controls were applied (Rindfuss et al. 2007). In addition, Kuziemko (2006) found that individuals in the US had a greater probability of having a child when a sister 
has had a child. As the effect was stronger if the siblings lived in close geographic proximity, Kuziemko attributed the observed effect to cost savings in shared childcare.

The second mechanism by which kin could influence fertility is through communicating information to their relatives that encourages reproduction (Newson et al. 2005). We will refer to this as "kin priming." Such priming could range from direct attempts at persuasion to more subtle influences on conversational topics and outcomes. Over time, these pro-natal messages by kin could lead kin-oriented social networks to develop norms that are more pro-natal. There have been few empirical investigations of such kin-priming effects. A notable exception used experimental manipulation of roleplaying scenarios to demonstrate that individuals gave more pro-natal advice to a hypothetical relative than to a hypothetical non-relative, but only in conditions favourable to reproduction (Newson et al. 2007).

Newson et al. argued that non-kin do not "spitefully encourage each other to behave in ways that detract from reproductive success" (2005: 370). However, as evolution is marked by competitive selection, it is possible that humans have evolved communication mechanisms to discourage the reproduction of their non-kin competitors. Alternatively, it may simply be the case that networks lacking kin also lack pro-natal messages. Regardless of the reason why, the aggregate pro-natal messages of kin suggested in Newson's theory were pro-natal only in contrast to the aggregate messages of non-kin.

The parties involved will not necessarily be consciously aware of this kin-priming influence. Numerous social psychological studies have shown that individual actors are often not consciously aware of the stimulus for their behaviour or attitudes (Nisbett and Wilson 1977; Zajonc 2000). Qualitative research in low-fertility settings (Rotkirch 2007; Bernardi, Mynarska, and Rossier 2010) has also shown that some individuals suddenly change from explicitly not wanting children to desiring them, and are then unable to articulate the reason for this change.

Our data do not allow us to provide clear answers to the question of whether resources or priming from kin cause the observed effect. However, in an attempt to explore these potential pathways of influence, we investigated whether the geographic proximity of kin or the frequency of contact with kin affected the risk of having a first birth. If geographic distance has a greater effect, then the main pathway may be potential childcare, as childcare can only be provided by those who have physical access to the child. Kin priming, on the other hand, simply requires communication with kin, so more frequent contact with relatives may increase the capacity for priming. 


\subsection{Potential confounding factors}

Socio-economic status (SES) could confound the relationship between the risk of first birth and kin-oriented social networks, if it were correlated with both fertility and association with kin. There is considerable evidence to suggest that SES affects fertility. Most research on contemporary British women has shown that higher SES is associated with delayed childbearing, increased childlessness, and reduced lifetime fertility (EkertJaffe et al. 2002; Rendall and Smallwood 2003; Berrington 2004; Ratcliffe and Smith 2006; Kneale and Joshi 2008; Nettle and Pollet 2008; Portanti and Whitworth 2009; Rendall et al. 2009), but also see (Kiernan 1989). Patterns of kin association may also differ between social classes, as greater education and employment opportunities increase social and geographic mobility. Higher socio-economic groups may be less kin-oriented. Recent empirical research in the UK has shown a negative association between SES and contact with kin, although the magnitude of this effect is often quite weak (Owen et al. 2004; Pahl and Pevalin 2005; Grundy and Murphy 2006; Nolan and Scott 2006; Murphy 2008). Moreover, these studies found that, across all socioeconomic strata, kin regularly form an important part of an individual's social network.

Nonetheless, in order to avoid any potential confounding, we controlled for SES in our models. We also attempted to control for several other potentially confounding factors, such as household composition, sibship size, religious and ethnic background, and geographical mobility. Like SES, these factors could be associated with both fertility and social network structure, and could thus confound any observed relationship. Household composition and sibship size partly determine the availability of kin for selection into a non-household social network. Household composition will be related to life course position. As noted previously, individuals who live with their parents are normally at lower risk of early childbearing. Similarly, sibship size and fertility may be related if there is any intergenerational transmission of fertility (Murphy 1999; Murphy and Wang 2001). In the UK, ethnic and religious groups often display quite different fertility and family formation patterns (Berthoud 2000; Coleman and Dubuc 2010), and these groups may also have different family and household structures (Connolly and Raha 2006). Residential mobility has been shown to influence fertility (Grundy 1986; Kulu and Milewski 2007), and, as was noted above, geographic proximity also affects family contact (Grundy and Murphy 2006).

Finally, we included a measure of the frequency of contact with all social network members (not just kin) in order to determine whether it was an individual's general level of social attachment, rather than interactions with kin, that might have caused any observed correlation between social network variables and the risk of first birth. 


\section{Data and methods}

For our analysis we used the on-going British Household Panel Study ${ }^{3}$ (BHPS). The panel started with 5,500 households in 1991, and had expanded to around 10,000 households by 2007. Information is collected in annual waves on each individual in the household. Our analysis is restricted to childless women who were at risk of having a first birth, defined as those who were aged 16 to 40 at the time of the interview. We used discrete-time event history analysis to analyse the risk of first birth, which allowed us to include censored cases and time-varying covariates (Allison 1984; BoxSteffensmeier and Jones 2004). Strictly speaking, we were analysing the timing of the first birth. However, as "perpetual postponement" is considered a key factor for the high levels of female childlessness in contemporary Europe (Berrington 2004), we assumed that if relatives influence the timing of a woman's first birth, they will also affect the chances that she will perpetually postpone having a child, and thus end up childless.

We confirmed the key assumptions of this method. The likelihood of the event is equal throughout the duration of each spell, and that the effects of the explanatory variables are equal across all spells, i.e., proportional hazards. Each spell in this case consists of a two-year period because our explanatory variable of interest, social network information, was collected in alternate years only, starting in 1992. We used only the first six occasions when this social network information was collected (we will refer to these collections as "waves") to allow sufficient time after the interview for the birth to occur. The "event" of interest was defined as a first birth to the respondent between nine and 27 months after the interview at that wave. We lagged the event in this way to exclude the possibility that women were pregnant when they were interviewed. We also ran the same models with a slightly different window of six to 24 months for the first birth, but this had little impact on the results (not shown ${ }^{4}$ ). Because social networks are labile over time, we did not want to extrapolate social network information before or after the collection of the data. Thus, women were considered at risk of having a first child only during the measurement period (1992-2003), and only first births which occurred during the measurement period or up to 27 months after the last wave were included. The birth history information was obtained from the consolidated family history file, as produced by Pronzato (2007). The age of the respondent at the time of the interview was included as a quadratic function. Each

${ }^{3}$ Full question wording, methodology and other documentation available at http://www.iser.essex.ac.uk/ survey/bhps. We were unable to find an satisfactory weighting so after consultation with staff at the BHPS we have used unweighted data with controls for sample extensions. We included all information available from the main sample and sample extentions. However as we were unable to fully control for other sampling biases in our panel, such as attrition, our results should not be interpreted as being fully nationally representative.

${ }^{4}$ All results not presented are available on request from the authors. 
model included categorical variables for the wave of data collection, although these were found to be consistently non-significant, and are thus not reported.

\subsection{Kin orientation and social networks}

Our goal was to determine whether women with closer kin ties were at greater risk of having a first child than those with looser kin ties. We considered individuals with greater kin orientation to be those with a higher proportion of kin in their close social network. The BHPS collects data on a respondent's close social network, consisting of the three individuals they would choose as their "closest friends." The BHPS includes the caveat that these friends "should not include people who live with you but they can include relatives." We will refer to the three closest individuals as the respondent's "friendship group." Respondents were asked whether each member of their friendship group was a relative, and our key measure of kin orientation was the number of relatives in the friendship group. Respondents only rarely answered that all three members were relatives, so the variable was capped at two and treated as a linear scale with units zero, one, and two. It should be noted that this description of relatives is subjective, not genetic, so non-genetic relatives, such as adopted children, step-siblings or step-parents, could also be included. Descriptive statistics for all of the variables included in the analysis are presented in Tables 1 and 2.

Table 1: Percentage of spells in which the respondent had the following number of individuals in her friendship group (\% by row)

\begin{tabular}{lccc}
\hline Number of & $\mathbf{0}$ & $\mathbf{1}$ & $\mathbf{2}$ or 3 \\
\hline relatives in friendship group & 2535 & 1241 & 406 \\
& $(60.6 \%)$ & $(29.7 \%)$ & $(9.7 \%)$ \\
friendship group members contacted "most days" & 1067 & 1394 & 1721 \\
& $(25.5 \%)$ & $(33.3 \%)$ & $(41.2 \%)$ \\
relatives in friendship group contacted "most days" & 3447 & 603 & 132 \\
& $(82.4 \%)$ & $(14.4 \%)$ & $(3.2 \%)$ \\
\hline
\end{tabular}


Mathews \& Sear: Kin orientation and entry into motherhood

Table 2: Descriptive statistics of other explanatory and control variables

\begin{tabular}{|c|c|c|c|}
\hline Descriptive statistics of other categorical variables & $\begin{array}{l}\text { Number of } \\
\text { spells }\end{array}$ & $\begin{array}{l}\text { Percentage of } \\
\text { spells }\end{array}$ & $\begin{array}{l}\text { Percentage of which } \\
\text { are followed } \\
\text { by a } 1^{\text {st }} \text { birth }\end{array}$ \\
\hline \multicolumn{4}{|l|}{ Distance and frequency of contact to relatives in the friendship group } \\
\hline No relatives in the friendship group & 1647 & 39.4 & 5.0 \\
\hline $\begin{array}{l}\text { Respondent had a relative in the friendship group who lived } \\
\text { over } 50 \text { miles away }\end{array}$ & 373 & 10.9 & 9.1 \\
\hline $\begin{array}{l}\text { Respondent had a relative in the friendship group who lived } \\
\text { within } 50 \text { miles and was not contacted "most days"5 }\end{array}$ & 526 & 15.3 & 11.4 \\
\hline $\begin{array}{l}\text { Respondent had a relative within } 50 \text { miles and this relative was } \\
\text { contacted "most days" }\end{array}$ & 497 & 14.5 & 14.5 \\
\hline \multicolumn{4}{|l|}{ Household contains } \\
\hline Only respondent & 567 & 13.56 & 2.8 \\
\hline Partner & 1403 & 33.6 & 16.2 \\
\hline Mother & 1770 & 42.3 & 3.5 \\
\hline Father & 1424 & 34.1 & 3.0 \\
\hline One or more sisters & 678 & 16.2 & 2.4 \\
\hline One or more brothers & 821 & 19.6 & 3.3 \\
\hline One or more non-relatives & 537 & 12.8 & 2.6 \\
\hline One or more other relatives & 119 & 2.9 & 7.6 \\
\hline \multicolumn{4}{|l|}{ Number of siblings (used as a continuous variable in model) } \\
\hline 0 & 315 & 7.5 & 7.3 \\
\hline 1 & 1509 & 36.1 & 8.0 \\
\hline 2 & 954 & 22.8 & 9.1 \\
\hline 3 & 366 & 8.8 & 8.7 \\
\hline 4 & 177 & 4.2 & 7.3 \\
\hline 5 & 80 & 1.9 & 7.5 \\
\hline 6 or more & 74 & 1.8 & 12.1 \\
\hline Missing & 707 & 16.9 & 2.4 \\
\hline
\end{tabular}

${ }^{5}$ Not measured in wave F. 
Table 2: (Continued)

\begin{tabular}{|c|c|c|c|}
\hline Descriptive statistics of other categorical variables & $\begin{array}{l}\text { Number of } \\
\text { spells }\end{array}$ & $\begin{array}{l}\text { Percentage of } \\
\text { spells }\end{array}$ & $\begin{array}{l}\text { Percentage of which } \\
\text { are followed by a } \\
1^{\text {st }} \text { birth }\end{array}$ \\
\hline Ever a member of a religious organisation & 578 & 13.8 & 8.5 \\
\hline Non-white ethnicity & 168 & 4.0 & 4.8 \\
\hline Internal migration from last wave & 245 & 5.9 & 5.7 \\
\hline Internal migration missing & 204 & 4.9 & 4.4 \\
\hline Respondent lives in England & 3765 & 90.0 & 7.2 \\
\hline Respondent lives in Scotland & 260 & 6.2 & 9.6 \\
\hline Respondent lives in Wales & 157 & 3.8 & 6.4 \\
\hline Cambridge Occupation Score of respondent's father: unavailable & 1622 & 38.8 & 5.2 \\
\hline Cambridge Occupation Score of respondent's mother: unavailable & 2185 & 52.3 & 6.9 \\
\hline Descriptive statistics of continuous variables & Mean & $\begin{array}{l}\text { Standard } \\
\text { Deviation }\end{array}$ & \\
\hline Age at time of interview (years) & 24.6 & 6.2 & \\
\hline Cambridge Occupation Score of respondent's father ${ }^{6}$ & 21.4 & 22.9 & \\
\hline Cambridge Occupation Score of respondent's mother & 17.9 & 22.4 & \\
\hline Number of individuals in the household (capped at 6) & 2.8 & 1.3 & \\
\hline
\end{tabular}

We assessed the frequency of interaction with friendship group members using answers to the question "How often do you see or get in touch with your friend either by visiting, writing or by telephone?" For each individual, we calculated the number of friendship group members who were contacted "most days" (set as a scale from zero to three) as a general measure of social attachment. A separate variable was constructed for the number of relatives who were contacted "most days," again capped at two, and used as an explanatory variable in some models; while the general measure of social attachment (number of friends contacted most days) was included in others (see Results) as a control variable to assess the possibility that it was the sociability of the respondents, rather than their kin orientation, which influenced the risk of birth.

${ }^{6}$ The higher the Cambridge Occupation Score, the higher the "status" of the occupation. 
The models were also run using dichotomised versions of the explanatory variables: i.e., variables that took into account whether the respondent had any relatives in the friendship group. We also checked the "frequency of contact" variables set at different thresholds. These operationalisations provided results similar to those of the scale versions (results not shown).

To determine whether the geographic proximity of relatives was important, we used answers to the question "About how many miles away does your friend live?" It would be harder for a relative to regularly provide practical support, such as childcare, if he or she lived over 50 miles away (the greatest distance among the response options). To assess the combined effects of frequency of contact and geographical proximity, we constructed three dummy variables for whether the friendship group contained the following: i) a relative living over 50 miles away, ii) a relative living closer than 50 miles but not contacted "most days," and iii) a relative living close by and contacted "most days" (respondents seldom reported being in frequent contact with a relative who lived over 50 miles away).

Finally, we analysed the effect of having a specific relative (a mother, a sister, etc.) within the friendship group. We did this by running separate models in which the sole explanatory variable was whether or not the specific relative had been named within the respondent's friendship group. All of the specific relatives were found to have had a non-significant effect (not shown). Unfortunately, this question and the geographic proximity question were not asked in wave F of the BHPS (1996), which substantially reduced our sample size for these models.

\subsection{Control variables}

Table 2 also includes descriptive statistics for our control variables. We controlled for the composition of the respondent's household at the time she reported her friendship group by including variables which specified whether a particular relative (i.e., partner, father, mother, one or more sisters, one or more brothers, one or more other relatives, or one or more other non-relatives) also lived in the household. In addition, we checked several alternative constructions of these variables (such as splitting siblings into younger and older categories), but these did not substantially change the results and thus are not reported. The total number of individuals in the household was included as a scale variable capped at six. 
We attempted to control for the number of non-household relatives. Unfortunately, information on the family outside the household was directly collected only at the very end of our study period, and there was a substantial amount of missing data. We were not able to control for parental mortality. We did include a variable for the number of siblings outside the household, but a large number of spells (16\%) were also missing a measure of sibship size.

We controlled for SES by including variables for the occupation of the respondent's mother and father when the respondent was 14 years old. We used the Cambridge Scale $\left(\right.$ CAMSIS $^{7}$ ) for the measurement of parental occupation. The Cambridge Scale is a continuous ranking of occupation groups, and is seen as a more modern and refined indicator of SES than the UK's Registrar-General classifications (Prandy 1999). Parental occupation is likely to give a more accurate impression of SES than the individual's own occupation or income, given that some respondents in our sample were still in education. Parental occupation also avoids the risk of endogeneity between individual SES and fertility: for example, women planning to have children in the near future may lower their investment in education or career progression. We did, however, check individual-level time-varying SES covariates for education, income, and occupation, and these control variables generated results similar to those produced using parental SES controls (results not shown). It should be noted that parental occupation was unavailable for a substantial number of respondents.

The BHPS is relatively ethnically homogenous, so we controlled for ethnicity using a simple dichotomous variable that indicated non-white ethnicity. Religiosity was defined as whether the respondent had ever reported being a member of a religious organisation. Internal migration was operationalised as whether a respondent had moved from a different region (broadly similar to the Government Office regions ${ }^{8}$ ) in the wave prior to the measurement of the friendship group.

${ }^{7}$ For details of its construction see http://www.camsis.stir.ac.uk/review.html.

${ }^{8}$ See http://www.statistics.gov.uk/geography/gor.asp for details of the UK statistical regions. 


\subsection{Other considerations}

Three different methods were used to control for missing data. First, for cases in which a substantial amount of data was missing, separate categorical dummy variables were included to compensate for the missing values (see Table 4). For example, for sibship size we imputed zero for missing values on the main variable; i.e., we assumed the respondent did not having any siblings, and then also included a separate dummy variable for these cases. For cases in which the number of missing observations was small, the missing values were imputed as the reference category. These are the results we present here. A complete case analysis and an imputation by chained equations (Schafer 1995) were also conducted. We also checked for attrition leading to nonreported births by running the models again, removing all spells in which the respondent's last interview (and therefore last opportunity to report a birth) was within 27 months of the measurement of the friendship group. All of these methods produced results similar to those presented, and are not shown.

Interactions were run between all of the control and friendship group variables. As these interactions proved to be non-significant or to have extremely large and noncredible coefficients (due to small cell sizes), they were not included in the final models. We confirmed the assumption of proportional hazards by considering interactions between all of the explanatory and control variables and age, and by analysing separately those older and younger than age 26 . There was no evidence that the effects of kin orientation varied by age. All of the analyses were conducted using Stata.

\section{Results}

The final dataset consisted of 1,590 female respondents who contributed a total of 4,182 spells. There were 307 (7.3\%) occasions in which the spell was followed by a first birth. Table 3 shows the bivariate association between the number of relatives in the friendship group and the first birth, which suggests that women with more kin in their friendship group were more likely to have had a first birth during the observation period than those with fewer close relatives (chi-square value $=61.7, \mathrm{p}<0.001$ ). Tables 4 and 5 show the multivariate models. We present nine models to show the effects of our main explanatory variables with and without the addition of various controls.

The regression parameters are presented in their exponentiated form. These relative risks represent the change in the risk of having a first child at any age relative to the variable's reference category. Categories where the exponentiated value is greater than one indicate an increase in the risk of first birth and values of less than one indicate 
a decreased risk of first birth, compared to the reference category. Model 1 included just the number of relatives in the friendship group, age, age squared, and the wave of data collection. This model showed that the women who had more relatives in their friendship group had a higher risk of having a first child at all ages. This effect was statistically significant at the $1 \%$ level. Unsurprisingly, the age terms indicate that the risk of first birth increased and then decreased with age.

Model 2 used the number of friendship group members contacted "most days," rather than any measure of kin orientation, to determine whether a general measure of social attachment might be influencing fertility. Unlike the composition of the friendship group, this measure of general social attachment had a very modest and nonsignificant influence on the risk of first birth. Model 3 included both of the above variables as well as controls for household composition and social cleavages. The kin orientation effect decreased in magnitude, although it remained significant at the 5\% level. The frequency of contact with the friendship group remained non-significant.

Model 4 showed that even when our main explanatory variable was limited to the number of frequently contacted relatives in the friendship group, kin orientation was still significantly and positively related to the risk of first birth. Model 5 showed the same effect, controlling for household composition, ethnicity, religion, and migration.

Unsurprisingly, of the control variables included in Models 3 and 5, living with a partner increased the risk of having a first child the most. The effect of having a mother in the household had a marginally significant association with an increased risk of first birth in some models, although this variable was no longer significant when controlling for sibship size. This variable should also be interpreted with caution, as relatively few women had a child while still living with their mother, and such cases may reflect uncaptured aspects of SES. Living with "other relatives" increased the risk of a first birth. This category was very heterogeneous - consisting of grandparents, uncles, aunts, half siblings, etc. - but there were too few cases to allow for a meaningful analysis of these relatives separately.

Models 6 and 7 included the parental socio-economic controls in the models. Including these controls had little impact on the kin orientation variables, which remained significant at the 5\% level. Increasing paternal occupational status significantly decreased the risk of first birth, while maternal occupational status did not have a significant effect. Rather surprisingly, we found that if the paternal occupation was missing there was a significantly lower risk of having a first birth. It is difficult to interpret this effect, and we suspect that it may simply result from associations between missingness, sample attrition, and the non-recording of births.

Finally, our results did not appear to be confounded with sibship size. In Models 8 and 9, sibship size was included in the models as a linear variable capped at six. The effects of our explanatory variables remained similar. The main effect of sibship size 
was not associated with risk of birth, but a dummy variable indicating missing sibship size was significantly associated with a lower risk of birth. We believe this may also be related to sample attrition.

Our secondary aim was to consider whether relatives' geographic proximity or frequency of contact had a greater effect on the risk of first birth. Model 10 showed the effect of having relatives in the friendship group at various combinations of geographic distance and contact frequency, with all of the control variables used in Model 9 also included. The results showed that the effect on the risk of first birth was statistically significant only in cases in which the respondent had a relative in the friendship group who lived within 50 miles, and this relative was seen frequently. It should be noted that this model did not include data from wave F (1996), and thus had a substantially smaller number of spells $(n=3,462)$. We also ran all of our preceding models with this subsample, and confirmed that there were no systematic differences between it and our main sample.

Table 3: Crosstab between the number of family members in the friendship group and whether the event ends in a birth (\% by column)

\begin{tabular}{lcc}
\hline & $\begin{array}{c}\text { Spells with no birth 9-27 } \\
\text { months afterwards }\end{array}$ & $\begin{array}{c}\text { Spell with a first birth 9-27 } \\
\text { months afterwards }\end{array}$ \\
\hline $\begin{array}{l}\text { Reporting no relatives in } \\
\text { friendship group }\end{array}$ & 2408 & 127 \\
& $(62.1 \%)$ & $(41.4 \%)$ \\
\hline $\begin{array}{l}\text { Reporting one relative in } \\
\text { friendship group }\end{array}$ & 1120 & 121 \\
& $(28.9 \%)$ & $(39.4 \%)$ \\
Reporting two or three relatives & 347 & 59 \\
in friendship group & $(9.0 \%)$ & $(19.2 \%)$ \\
\hline
\end{tabular}


Table 4: Relative risk of a first birth from multivariate discrete-time event history analysis models, with the number of family members in the friendship group as the main explanatory variable

\begin{tabular}{|c|c|c|c|c|c|}
\hline & Model 1 & Model 2 & Model 3 & Model 6 & Model 8 \\
\hline Number of relatives in friendship group & $1.58^{* * *}$ & & $1.21^{\star *}$ & $1.21^{\star \star}$ & $1.21^{\star \star}$ \\
\hline Number of friendship group contacted "most days" & & 0.99 & 1.06 & 1.04 & 1.03 \\
\hline \multicolumn{6}{|l|}{ Household contains (ref: Lives alone) } \\
\hline Partner & & & $6.27^{\star \star \star}$ & $6.07^{\star * *}$ & $5.88^{\star \star \star}$ \\
\hline Mother & & & $1.73^{*}$ & $1.78^{*}$ & 1.69 \\
\hline Father & & & 0.66 & 0.61 & 0.64 \\
\hline One or more sisters & & & 0.64 & 0.64 & 0.61 \\
\hline One or more brothers & & & 1.02 & 1.01 & 0.98 \\
\hline One or more non-relatives & & & 0.56 & 0.56 & 0.61 \\
\hline One or more other relatives & & & $2.99^{* * *}$ & $3.08^{* * *}$ & $2.95^{\star *}$ \\
\hline Household size (capped at 6) & & & 1.02 & 1.00 & 0.99 \\
\hline $\begin{array}{l}\text { Ever a member of a religious organisation } \\
\quad \text { (ref: never a member) }\end{array}$ & & & 1.10 & 1.18 & 1.13 \\
\hline Non-white ethnicity (ref: white ethnicity) & & & 0.96 & 0.96 & 0.94 \\
\hline Internal migration from last wave (ref: no migration) & & & 0.88 & 0.88 & 0.83 \\
\hline Internal migration missing & & & $0.53^{*}$ & 0.58 & 0.78 \\
\hline Respondent lives in Scotland (ref: England) & & & 1.29 & 1.29 & 1.37 \\
\hline Respondent lives in Wales (ref: England) & & & 0.81 & 0.83 & 0.85 \\
\hline Cambridge Occupation Score of respondent's father & & & & $0.99 * *$ & $0.99^{*}$ \\
\hline Cambridge Occupation Score of respondent's mother & & & & 1.00 & 1.00 \\
\hline $\begin{array}{l}\text { Cambridge Occupation Score of respondent's father: } \\
\text { missing }\end{array}$ & & & & $0.54^{\star \star *}$ & $0.62^{* *}$ \\
\hline $\begin{array}{l}\text { Cambridge Occupation Score of respondent's mother: } \\
\text { missing }\end{array}$ & & & & 1.26 & 1.23 \\
\hline Number of siblings (capped at 6) & & & & & 1.07 \\
\hline $\begin{array}{l}\text { Number of siblings missing } \\
\text { (ref: sibling information is available) }\end{array}$ & & & & & $0.31^{* \star *}$ \\
\hline Age & $1.86^{* * *}$ & $2.01^{* * *}$ & $1.33^{* \star *}$ & $1.29 * *$ & $1.33^{* *}$ \\
\hline $\mathrm{Age}^{2}$ & $0.99^{* * *}$ & $0.99^{* * *}$ & $0.99^{* * *}$ & $0.99^{* * *}$ & $0.99^{* *}$ \\
\hline
\end{tabular}

Note: Controlling for wave of collection (non-significant in all models) ${ }^{\star \star *} p<0.01 ;{ }^{* *} p<0.05 ;{ }^{*} p<0.1$. 
Mathews \& Sear: Kin orientation and entry into motherhood

\section{Table 5: $\quad$ Relative risk of first birth from multivariate discrete-time event history analysis models with the frequency of contact with relatives included as the explanatory variable}

\begin{tabular}{|c|c|c|c|c|c|}
\hline & Model 4 & Model 5 & Model 7 & Model 9 & Model $10^{9}$ \\
\hline Number of relatives contacted "most days" in friendship group & $1.62^{\star \star \star}$ & $1.30^{* *}$ & $1.28^{* \star}$ & $1.26^{\star *}$ & \\
\hline A relative in the friendship group who lived over 50 miles away & & & & & 1.24 \\
\hline \multicolumn{6}{|l|}{ A relative in the friendship group within 50 miles } \\
\hline Not contacted "most days" & & & & & 1.14 \\
\hline Contacted "most days" & & & & & $1.48^{\star *}$ \\
\hline \multicolumn{6}{|l|}{ Household contains (ref: lives alone) } \\
\hline Partner & & $6.30^{\star * *}$ & $6.14^{\star \star \star}$ & $6.00^{* * *}$ & $6.81^{\star \star \star}$ \\
\hline Mother & & 1.69 & $1.75^{*}$ & 1.67 & 1.74 \\
\hline Father & & 0.67 & 0.61 & 0.66 & 0.84 \\
\hline One or more sisters & & 0.64 & 0.64 & 0.62 & 0.72 \\
\hline One or more brothers & & 1.02 & 1.01 & 0.99 & 0.97 \\
\hline One or more non-relatives & & 0.57 & 0.56 & 0.60 & 0.69 \\
\hline One or more other relatives & & $3.03^{* * *}$ & $3.11^{* \star \star}$ & $2.99^{* * *}$ & $3.39^{\star \star \star}$ \\
\hline Household size (capped at 6) & & 1.02 & 1.00 & 0.99 & 0.84 \\
\hline Ever a member of a religious organisation (ref: never a member) & & 1.10 & 1.17 & 1.13 & 1.13 \\
\hline Non-white ethnicity (ref: white ethnicity) & & 0.95 & 0.94 & 0.93 & 0.69 \\
\hline Internal migration from last wave (ref: no migration) & & 0.87 & 0.87 & 0.83 & 0.72 \\
\hline Internal migration missing & & $0.52^{*}$ & 0.57 & 0.78 & 0.70 \\
\hline Respondent lives in Scotland (ref: England) & & 1.25 & 1.26 & 1.35 & $1.74^{* *}$ \\
\hline Respondent lives in Wales (ref: England) & & 0.80 & 0.81 & 0.84 & 0.92 \\
\hline Cambridge Occupation Score of respondent's father & & & $0.99^{* *}$ & $0.99^{*}$ & 0.99 \\
\hline Cambridge Occupation Score of respondent's mother & & & 1.00 & 1.00 & 1.00 \\
\hline Cambridge Occupation Score of respondent's father: missing & & & $0.55^{\star \star \star}$ & $0.62^{* *}$ & 0.69 \\
\hline Cambridge Occupation Score of respondent's mother: missing & & & 1.27 & 1.24 & 1.18 \\
\hline Number of siblings (capped at 6) & & & & 1.07 & $1.10^{*}$ \\
\hline Number of siblings missing (ref: sibling information is available) & & & & $0.32^{* * *}$ & $0.32^{\star \star *}$ \\
\hline Age & $1.91^{\star \star *}$ & $1.32^{* *}$ & $1.28^{* *}$ & $1.32^{* *}$ & 1.22 \\
\hline $\mathrm{Age}^{2}$ & $0.99^{\star \star \star}$ & $0.99^{* \star *}$ & $0.99^{\star *}$ & $0.99^{* \star *}$ & $0.99^{\star \star}$ \\
\hline
\end{tabular}

Note: Controlling for wave of collection (non-significant in all models) ${ }^{\star \star \star} p<0.01$; ${ }^{* \star} p<0.05$; ${ }^{\star} p<0.1$.

${ }^{9}$ Wave $\mathrm{F}$ was excluded from analysis in this model. 


\section{Discussion}

Our results showed that the more relatives a woman reported within her circle of three closest friends, the greater the risk that she would have a first child. A similar association was observed between the risk of first birth and the number of relatives in the group of the three closest friends who are regularly contacted. However, there did not seem to be any association between the risk of first birth and a woman's overall level of social attachment, as measured by the frequency of contact she had with her friends in general.

Our initial models showed a strong relationship between first birth risk and social network composition, controlling for age only. While the effect size decreased in subsequent models, largely due to the inclusion of household composition variables, the association between kin orientation and fertility remained statistically significant, even after controlling for numerous factors. It is noteworthy that social network composition variables were significant predictors of first birth whilst factors such as ethnicity and religiosity were not significant predictors.

Our research has value for demographers interested in the influence of social networks on fertility. While we were not able to look in detail at the fertility of the friendship group members, which would have been necessary if we had been studying the question of whether the observed effect was due to respondents conforming to childbearing patterns within their networks (i.e., the degree of social influence), we believe this study highlights the importance of explicitly considering the relatedness of a social network. Friends and family were shown to have different effects.

Our data did not allow us to reach any firm conclusions about the proximate mechanisms through which kin influence fertility, but we attempted to investigate this issue by constructing a set of variables which combined geographic proximity and frequency of contact with kin. After comparing frequently and infrequently contacted relatives who lived within 50 miles of the respondent, we found that only the frequently contacted relatives significantly increased the risk of first birth. This implies that communication between kin is necessary for kin to influence fertility, and perhaps suggests that, rather than the effect simply being due to the prospect of receiving childcare or other resources from a relative, kin priming plays an important role. Note that even relatives who were contacted 'infrequently' were still considered by the respondent to be amongst her three closest friends.

However, attempting to distinguish between resources and information provided by kin prior to the first birth may create a slightly artificial dichotomy. Frequently contacted relatives could be seen as more likely to provide practical support, such as childcare. Other kin assistance, such as post-natal emotional support, advice, or financial help, does not require geographic proximity. It is also quite possible, and is 
indeed probable, that the resources provided by kin could be an important factor in the progression to later births, when childcare has become a practical reality. Finally, as "cooperative breeding" was probably an essential feature of the human evolutionary trajectory (Hrdy 2009), communications with kin could have a deeper psychological impact on a woman's assessment of her reproductive resources, over and above any conscious calculation of childcare costs. Having children is a life-changing and potentially risky decision. Some women may require assurances from others before starting childbearing. In addition to her partner, a woman's relatives are likely to form a critical component in her resource network. This may well make their assurances particularly influential.

We were surprised that no significant effects were found for any of the specific relatives included in the friendship group, given that previous research by evolutionary anthropologists has had success in identifying the influence of specific relatives (see reviews by Mace and Sear (2005) and Sear and Coall (2011)). Our study differs from this previous work, however, in that we tested for the influence of specific relatives who resided outside of the household, thereby excluding the influence of those living within the household. It is still possible that the influence of relatives will differ based on differences in life course position and degrees of relatedness, and that the failure to reach statistical significance could be due to an insufficient number of observations for each type of relative.

Ideally, kin orientation variables should be obtained from a continuously recorded measure of all contacts over the entirety of an individual's social network, combined with additional measures of the influence and strength of the contact and precise measures of genetic relatedness. However, such data are not readily available, and certainly not at the nationally representative level. The friendship group used in this study constitutes a social network operationalised at a very close ego-centric level. Defined as just the three closest non-household individuals, it is not directly comparable to other conceptualisations of close social networks, such as the "support clique" (Dunbar and Spoors 1995) or the "personal community" (Pahl 2005). It would not necessarily be appropriate to assume that the kin orientation of this stratum of the network would be reflected outwards, although Dunbar and Spoors (1995) have argued that this is likely to be the case.

Our study has other limitations. It was not possible to properly control for the size of the pool of relatives outside of the household who were available for selection into the friendship group, although we attempted to do so in part by controlling for sibship size. And while we attempted to control for missingness as fully as possible, it remains a concern that the control variables for missing sibship size and paternal occupation were significantly associated with a reduced risk of a recorded first birth. The 
measurement of "relatives" was also limited, as it may have included social relatives such as step-siblings.

Finally, our association between social network composition and fertility remained robust to the inclusion of numerous variables that seek to control for SES and the other social cleavages, but it is possible there were unobserved confounding variables, such as personality, that may have influenced both fertility and social network construction. In addition, reverse causation may be an issue if a woman became closer to her relatives, especially to her parents, in preparation for the onset of childbearing. While this is possible, the substantial time lag (up to 18 months between the measurement of the family group and conception) would indicate a level of forward planning not generally seen in the qualitative descriptions of fertility decision-making (Rotkirch 2007; Bernardi, Mynarska, and Rossier 2010). Moreover, both personality differences and reverse causation would remain consistent with the central theme of this paper: family is important for childbearing and childrearing.

Kinship is one of the fundamental cornerstones of human society, and has been throughout our evolutionary history. Even in a complex contemporary society, its influence is felt in one of the most important questions an individual faces in his or her adult life: whether and when to become a parent.

\section{Acknowledgments}

This work was funded by the UK Economic and Social Research Council. The authors would like to thank the Institute for Social and Economic Research and the UK Data Archive for making the data available, and Chiara Pronzato for compiling the BHPS fertility histories dataset. The authors are very grateful to all those who have provided comments on the paper, in particular the LSE's evolution work in progress group and population cluster. A special acknowledgement is given to Dr Wendy Sigle-Rushton for her many helpful suggestions.

\section{Corrections:}

On February 20, 2013 twelve typing mistakes were corrected on pages 313, 316, 320, $321,323,324,325,326,327$, and on page 330. 


\section{References}

Allison, P.D. (1984). Event History Analysis: Regression for longitudinal event data. Newbury Park: Sage Publications.

Avogo, W. and Agadjanian, V. (2008). Men's Social Networks and Contraception in Ghana. Journal of Biosocial Science 40(3): 413-429. doi:10.1017/S0021932007002507.

Behrman, J.R., Kohler, H.P., and Watkins, S.C. (2002). Social networks and changes in contraceptive use over time: Evidence from a longitudinal study in rural Kenya. Demography 39(4): 713-738. doi:10.1353/dem.2002.0033.

Bernardi, L. (2003). Channels of social influence on reproduction. Population Research and Policy Review 22(5-6): 527-555. doi:10.1023/B:POPU.0000020892. 15221.44 .

Bernardi, L., Mynarska, M., and Rossier, C. (2010). Intentions, unvertainty and ambivalence in fertility decisions. Paper presented at the European Population Conferece, Vienna, September 1-4 2010.

Berrington, A. (2004). Perpetual postponers? Women's, men's and couple's fertility intentions and subsequent fertility behaviour. Population Trends 117: 9-19.

Berthoud, R. (2000). Family Formation in Multi-cultural Britain: Three patterns of diversity. Colchester: Institute of Social and Economic Research. (ISER Working Paper).

Borgerhoff Mulder, M. (2009). Tradeoffs and sexual conflict over women's fertility preferences in Mpimbwe. American Journal of Human Biology 21(4): 478-487. doi:10.1002/ajhb.20885.

Box-Steffensmeier, J.M. and Jones, B.S. (2004). Event history modeling : A guide for social scientists. Cambridge: Cambridge University Press.

Boyd, R. and Richerson, P.J. (1985). Culture and the Evolutionary Process. Chicago: University of Chicago Press.

Burch, T.K. and Gendell, M. (1970). Extended Family Structure and Fertility: Some Conceptual and Methodological Issues. Journal of Marriage and Family 32(2): 227-236. doi:10.2307/350128.

Cleland, J. and Wilson, C. (1987). Demand theories of the fertility transition: An iconoclastic view. Population Studies 41(1): 5-30. doi:10.1080/0032472 031000142516. 
Coleman, D.A. and Dubuc, S. (2010). The fertility of ethnic minorities in the UK, 1960s-2006. Population Studies: A Journal of Demography 64(1): 19-41. doi:10.1080/00324720903391201.

Connolly, H. and Raha, C. (2006). Chapter 4: Households and families. In: Dobbs, J., Green, H. and Zealey, L. (eds.). Focus on Ethnicity and Religion. Basingstoke, Hampshire: Palgrave Macmillan: 83-10.

Davis, K. and Blake, J. (1956). Social Structure and Fertility: An Analytic Framework. Economic Development and Cultural Change 4(3): 211-235. doi:10.1086/ 449714.

Del Boca, D. (2002). The effect of child care and part time opportunities on participation and fertility decisions in Italy. Journal of Population Economics 15(3): 549-573. doi:10.1007/s001480100089.

Dunbar, R. and Spoors, M. (1995). Social networks, support cliques, and kinship. Human Nature 6(3): 273-290. doi:10.1007/BF02734142.

Ekert-Jaffe, O., Joshi, H., Lynch, K., Mougin, R., Rendall, M., and Shapiro, D. (2002). Fertility, Timing of Births and Socio-economic Status in France and Britain: Social Policies and Occupational Polarization. Population (English Edition, 2002-) 57(3): 475-507. doi:10.2307/3246636.

Gray, A. (2005). The Changing Availability of Grandparents as Carers and its Implications for Childcare Policy in the UK. Journal of Social Policy 34(04): 557-577. doi:10.1017/S0047279405009153.

Grundy, E. (1986). Migration and fertility behaviour in England and Wales: A record linkage study. Journal of Biosocial Science 18(04): 403-423. doi:10.1017/S0021932000016436.

Grundy, E. and Murphy, M. (2006). Kin Availability, Contact and Support Exchanges Between Adult Children and their Parents in Great Britain. In: Ebtehaj, F., Lindley, B. and Richards, M. (eds.). Kinship Matters. Oxford: Hart Publishing: 195-215.

Hamilton, W.D. (1964). The genetical evolution of social behaviour. I. Journal of Theoretical Biology 7(1): 1-16. doi:10.1016/0022-5193(64)90038-4.

Hank, K. and Kreyenfeld, M. (2003). A Multilevel Analysis of Child Care and Women's Fertility Decisions in Western Germany. Journal of Marriage and Family 65(3): 584-596. doi:10.1111/j.1741-3737.2003.00584.x. 
Helleringer, S. and Kohler, H.-P. (2005). Social Networks, Perceptions of Risk, and Changing Attitudes Towards HIV/AIDS: New Evidence from a Longitudinal Study Using Fixed-Effects Analysis. Population studies 59(3): 265-282. doi:10.1080/00324720500212230.

Hensvik, L. and Nilsson, P. (2010). Businesses, buddies and babies: social ties and fertility at work. Uppsala: Institute for Labour Market Policy Evaluation. (Working Paper Series).

Hrdy, S. (2009). Mothers and Others: The Evolutionary Origins of Mutual Understanding. Harvard University Press.

Keim, S., Klarner, A., and Bernardi, L. (2009). Qualifying Social Influence on Fertility Intentions: Composition, Structure and Meaning of Fertility-relevant Social Networks in Western Germany. Current Sociology 57(6): 888-907. doi:10.1177/0011392109342226.

Kiernan, K.E. (1989). Who remains childless? Journal of Biosocial Science 21(04): 387-398. doi:10.1017/S0021932000018125.

Kiernan, K.E. (1992). The Impact of Family Disruption in Childhood on Transitions Made in Young Adult Life. Population Studies: A Journal of Demography 46(2): 213-234. doi:10.1080/0032472031000146206.

Kiernan, K.E. and Hobcraft, J. (1997). Parental Divorce during Childhood: Age at First Intercourse, Partnership and Parenthood. Population Studies 51(1): 41-55. doi:10.1080/0032472031000149716.

Kneale, D. and Joshi, H. (2008). Postponement and childlessness - Evidence from two British cohorts. Demographic Research 19(58): 1935-1968. doi:10.4054/ DemRes.2008.19.58.

Kohler, H.-P., Behrman, J.R., and Watkins, S.C. (2000). Empirical assessments of social networks, fertility and family planning programs: nonlinearities and their implications. Demographic Research 3(7). doi:10.4054/DemRes.2000.3.7.

Kohler, H.P. (1997). Learning in social networks and contraceptive choice. Demography 34(3): 369-383. doi:10.2307/3038290.

Kohler, H.P., Behrman, J.R., and Watkins, S.C. (2001). The density of social networks and fertility decisions: Evidence from South Nyanza District, Kenya. Demography 38(1): 43-58. doi:10.1353/dem.2001.0005.

Kulu, H. and Milewski, N. (2007). Interdependencies in the life course: family, fertility, and migration. Rostock: MPIDR. 
Kuziemko, I. (2006). Is Having Babies Contagious? Estimating Fertility Peer Effects Between Siblings. Yale University.

Mace, R. and Colleran, H. (2009). Kin influence on the decision to start using modern contraception: A longitudinal study from rural Gambia. American Journal of Human Biology 21(4): 472-477. doi:10.1002/ajhb.20940.

Mace, R. and Sear, R. (2005). Are humans cooperative breeders? In: Voland, E., Chasiotis, A., and Schiefenhoevel, W. (eds.). Grandmotherhood: The Evolutionary Significance of the Second Half of Female Life. New Brunswick: Rutgers University Press: 143-159.

Madhavan, S., Adams, A., and Simon, D. (2003). Women's networks and the social world of fertility behavior. International Family Planning Perspectives 29(2): 58-68. doi:10.2307/3181059.

Manlove, J. (1997). Early Motherhood in an Intergenerational Perspective: The Experiences of a British Cohort. Journal of Marriage and Family 59(2): 263279. doi: $10.2307 / 353469$.

Montgomery, M.R. and Casterline, J.B. (1993). The Diffusion of Fertility-Control in Taiwan - Evidence from Pooled Cross-Section Time-Series Models. Population Studies: A Journal of Demography 47(3): 457-479. doi:10.1080/00324 72031000147246.

Montgomery, M.R. and Casterline, J.B. (1996). Social Learning, Social Influence, and New Models of Fertility. Population and Development Review 22: 151-175. doi: $10.2307 / 2808010$.

Montgomery, M.R. and Chung, W. (1999). Social Networks and the Diffusion of Fertility Control in the Republic of Korea. In: Leete, R. (ed.). Dynamics of Values in Fertility Change. Oxford: Oxford University: 179-209.

Murphy, M. (1999). Is the relationship between fertility of parents and children really weak? Biodemography and Social Biology 46(1-2): 122-145. doi:10.1080/ 19485565.1999.9988991.

Murphy, M. (2008). Variations in Kinship Networks Across Geographic and Social Space. Population and Development Review 34(1): 19-49. doi:10.1111/j.17284457.2008.00204.x.

Murphy, M. and Wang, D.L. (2001). Family-level continuities in childbearing in lowfertility societies. European Journal of Population 17(1): 75-96. doi:10.1023/A:1010744314362. 
Musalia, J.M. (2006). Gender, children and family planning networks in Kenya. Social Science Journal 43(1): 167-172. doi:10.1016/j.soscij.2005.12.014.

Nettle, D. and Pollet, T.V. (2008). Natural Selection on Male Wealth in Humans. The American Naturalist 172(5): 658-666. doi:10.1086/591690.

Newson, L., Postmes, T., Lea, S.E.G., Webley, P., Richerson, P.J., and Mcelreath, R. (2007). Influences on communication about reproduction: The cultural evolution of low fertility. Evolution and Human Behavior 28(3): 199-210. doi:10.1016/j.evolhumbehav.2007.01.003.

Newson, L., Postmes, T., Lea, S.E.G., and Webley, P. (2005). Why are modern families small? Toward an evolutionary and cultural explanation for the demographic transition. Personality and Social Psychology Review 9(4): 360-375. doi:10.1207/s15327957pspr0904_5.

Nisbett, R.E. and Wilson, T.D. (1977). Telling more than we can know: Verbal reports on mental processes. Psychological Review 84(3): 231-259. doi:10.1037//0033295X.84.3.231.

Nolan, J. and Scott, J. (2006). Gender and Kinship in Contemporary Britain. In: Ebtehaj, F., Lindley, B. and Richards, M. (eds.). Kinship Matters. Oxford: Hart Publishing: 175-194.

Owen, C., Mooney, A., Brannen, J., and Statham, J. (2004). Wider Family. In: Dex, S. and Joshi, H. (eds.). Millennium Cohort Study First Survey: A User's Guide to Initial Findings. Centre for Longitudinal Studies Bedford Group for Lifecourse \& Statistical Studies Institute of Education, University of London: 51-74.

Pahl, R. (2005). Are all communities communities in the mind? The Sociological Review 53(4): 621-640. doi:10.1111/j.1467-954X.2005.00587.x.

Pahl, R. and Pevalin, D.J. (2005). Between family and friends: A longitudinal study of friendship choice. British Journal of Sociology 56(3): 433-451. doi:10.1111/j.1468-4446.2005.00076.x.

Portanti, M. and Whitworth, S. (2009). A comparison of the characteristics of childless women and mothers in the ONS Longitudinal Study. Population Trends 136(1): 10-20. doi:10.1057/pt.2009.15.

Prandy, K. (1999). Class, stratification and inequalities in health: A comparison of the Registrar-General's Social Classes and the Cambridge Scale. Sociology of Health \& Illness 21(4): 466-484. doi:10.1111/1467-9566.00167. 
Pronzato, C. (2007). British Household Panel Survey Consolidated Marital, Cohabitation and Fertility Histories, 1991-2006. Colchester: Institute of Social and Economic Research. (ISER Working Paper).

Ratcliffe, A. and Smith, S. (2006). Fertility and women's education in the UK: A cohort analysis. (CMPO Working Paper).

Rendall, M. and Smallwood, S. (2003). Higher Qualifications, First Birth Timing, and Further Childbearing in England and Wales. Population Trends 111: 18-26.

Rendall, M.S., Ekert-Jaffé, O., Joshi, H., Lynch, K., and Mougin, R. (2009). Universal versus Economically Polarized Change in Age at First Birth: A French and British Comparison. Population and Development Review 35(1): 89-115. doi:10.1111/j.1728-4457.2009.00262.x.

Rindfuss, R.R., Choe, M.K., Bumpass, L.L., and Tsuya, N.O. (2004). Social Networks and Family Change in Japan. American Sociological Review 69(6): 838-861. doi:10.1177/000312240406900605.

Rindfuss, R.R., Guilkey, D., Morgan, S.P., Kravdal, Ø., and Guzzo, K.B. (2007). Child Care Availability and First-Birth Timing in Norway. Demography 44(2): 345372. doi:10.1353/dem.2007.0017.

Rotkirch, A. (2007). All that she wants is a(nother) baby'? Longing for children as a fertility incentive of growing importance. Journal of Evolutionary Psychology 5(1): 89-104. doi:10.1556/JEP.2007.1010.

Ruggles, S. (1994). The Transformation of American Family Structure. The American Historical Review 99(1): 103-128. doi:10.2307/2166164.

Russell, S.T. (1994). Life Course Antecedents of Premarital Conception in Great Britain. Journal of Marriage and Family 56(2): 480-492. doi:10.2307/353114.

Sandberg, J. (2005). The Influence of Network Mortality Experience on Nonnumeric Response Concerning Expected Family Size: Evidence from a Nepalese Mountain Village. Demography 42(4): 737-756. doi:10.1353/dem.2005.0035.

Schafer, J.L. (1995). Analysis of incomplete multivariate data. Bury St Edmunds: Chapman \& Hall.

Sear, R. and Coall, D. (2011). How Much Does Family Matter? Cooperative Breeding and the Demographic Transition. Population and Development Review 37: 81112. doi:10.1111/j.1728-4457.2011.00379.x. 
Sear, R. and Mathews, P. (2009). The impact of kin on female fertility: A systematic review. Paper presented at the International Union for the Scientific Study of Population, Marrakesh, Morocco, 28 September - 2 October 2009.

Turke, P.W. (1989). Evolution and the demand for children. Population and Development Review 15(1): 61-90. doi:10.2307/1973405.

Wheelock, J. and Jones, K. (2002). 'Grandparents Are the Next Best Thing': Informal Childcare for Working Parents in Urban Britain. Journal of Social Policy 31(03): 441-463. doi:10.1017/S0047279402006657.

Young, M. and Wilmott, P. (1957). Family and Kinship in East London. London: Penguin.

Zajonc, R.B. (2000). Feeling and thinking : Closing the Debate Over the Independence of Affect. In: Forgas, J.P. (ed.). Feeling and thinking : The role of affect in social cognition. Cambridge, U.K: Cambridge University Press: 31-58. 